\title{
A Simulation Study for Trimetallic Nanosized Alloy (Ni, Cu, and Ag) in Hydrogenation of Organic Compounds: A Case Study of "Nitrophenols"
}

\author{
Salem M. Bawaked, ${ }^{1}$ Islam Hamdy Abd El Maksod, ${ }^{1,2}$ and Abdulmohsen Alshehri' \\ ${ }^{1}$ Faculty of Science, Department of Chemistry, King Abdulaziz University, Jeddah, Saudi Arabia \\ ${ }^{2}$ National Research Centre, Physical Chemistry Department, Dokki, Cairo, Egypt \\ Correspondence should be addressed to Islam Hamdy Abd El Maksod; islam_9000@yahoo.com
}

Received 4 December 2016; Revised 5 January 2017; Accepted 16 February 2017; Published 13 March 2017

Academic Editor: Mohamed Bououdina

Copyright ( 92017 Salem M. Bawaked et al. This is an open access article distributed under the Creative Commons Attribution License, which permits unrestricted use, distribution, and reproduction in any medium, provided the original work is properly cited.

\begin{abstract}
Trimetallic system $(\mathrm{Ni}, \mathrm{Cu}$, and $\mathrm{Ag}$ ) supported on alumina was utilized for hydrogenation of nitrophenols. The catalytic active centers for hydrogenation were attributed only to the presence of Ni. However, the presence of bi- or trimetallic systems improves the catalytic activity via extra synergism. The catalytic activity was measured as the time for reaching $100 \%$ conversion. The function of synergism was fitted for both bimetallic systems (Ni:Ag; Ni:Cu) individually. Subsequently, three-dimensional function was fitted for trimetallic system ( $\mathrm{Ni}: \mathrm{Cu}: \mathrm{Ag}$ ) based on the linear combination of data for individual bimetallic system. After a complex calculation areal function was evaluated. An Excel program was written to simply evaluate the catalytic activity of trimetallic system with high accuracy. Characterization of catalysts was performed using EPR and pulsed chemisorption by hydrogen. These characterizations of samples enable us to evaluate particle size, metallic surface area, and degree of dispersion. These values were successfully correlated with the synergism function. The program written then could be capable of predicting these values for any trimetallic system.
\end{abstract}

\section{Introduction}

Hydrogenation reactions are one of the most important reactions for preparation of many fine chemicals and important intermediates [1-5]. The selectivity and activity of such reactions are an issue of most recent researches [1, 2]. Most of catalysts used in such important reactions are metal catalysts $[6,7]$. The basic idea of hydrogenation reactions is to adsorb both metal and target organic moiety subject to hydrogenation. The challenge in this subject is to find that metal has high activity and selectivity towards the desired compound. In order to attain both activity and selectivity researches tend to use bimetallic system. Thus, a combination of $\mathrm{Ni}-\mathrm{Ag}, \mathrm{Ni}-\mathrm{Cu}$, and $\mathrm{Ni}-\mathrm{Au}$ was used in [1] for active and selective hydrogenation of cinnamaldehyde. In addition, $\mathrm{Ni}$ Pd bimetallic system was used in hydrogenation of nitrobenzyl ethers to amino benzyl [2]. Moreover, Ni-Ag bimetallic system was used in hydrogenation of dimethyl oxalate [3].
Many others researches also used many combinations of bimetallic systems in order to enhance the selectivity and activity [4-8]. Searching the literature data, only few papers deal with the trimetallic system. Thus, in [9] homogenous catalyst containing trimetallic system of $\mathrm{Sn}, \mathrm{Ru}, \mathrm{Pt}$ in selective reduction of cyclodecatriene. However heterogeneous catalyst containing clusters of $\mathrm{PtRu}_{5} \mathrm{Sn}$ was evaluated as hydrogenation catalyst $[10,11]$. Just as rare sole example we found a paper that deals with hetero quarter metallic nanoparticle hydrogenation catalyst of $\mathrm{Ni} / \mathrm{Ru} / \mathrm{Pt} / \mathrm{Au}$ [12]. In all above examples of hydrogenation catalysts containing bi- or tri- or even quaternary metallic systems a simple evaluation of one sample or more is performed just to bring the selectivity and compare it to bi- or monometallic catalyst. In this paper we aim to investigate and write a mathematical simulation program containing trimetallic heterogeneous catalyst containing $\mathrm{Ni}, \mathrm{Ag}$, and $\mathrm{Cu}$. 
In order to fulfill this purpose, we choose a simple effective hydrogenation reaction. Thus hydrogenation of nitrophenol into amino phenol using supported metal and using hydrazine hydrate as a hydrogen source was proven to be $100 \%$ selective and finishes with $100 \%$ conversion in only few minutes $[13,14]$. The program will evaluate the effect of this trimetallic system and will build three-dimensional model for the activity function of these catalysts and also will be capable of evaluating some physical properties of these metals.

\section{Experimental}

2.1. Materials Used. $\mathrm{NaOH}$ (Merck), copper nitrate (Merck), nickel nitrate (Merck), silver(I) nitrate (Merck), hydrazine hydrate (99.999\% Merck), alumina (FLUKA Typ 507c), Pnitrophenol (PNP) (Merck), o-nitrophenol (oNP) (Merck), m-nitrophenol (mNP) (Merck), P-aminophenol (PAP) (Merck), m-aminophenol (mAP) (Merck), and o-aminophenol (oAP) (Merck) were used as a standard materials.

\subsection{Preparation of the Catalyst. Typically $10 \mathrm{~g}$ of alumina was} impregnated with $5 \mathrm{wt} \%$ metals. Different mole ratios of mono-, di-, and trimetal are varied keeping $5 \mathrm{wt} \%$ constant. After drying at $100^{\circ} \mathrm{C}$ the catalyst is subjected to chemical reduction using hydrazine hydrate in alkaline solution of $\mathrm{NaOH}$. After completion of reduction, the catalyst was rapidly filtered and dried and kept in a closed bottle.

2.3. Catalytic Reaction. Typically, a solution containing $0.125 \mathrm{~g}$ of nitrophenols with $20 \mathrm{~mL}$ of hydrazine hydrate was heated to $80-100^{\circ} \mathrm{C}$ in a three-necked flask connected to a condenser.

$0.5 \mathrm{~g}$ of the catalyst was added to the above solution. The time was recorded just upon the addition. After reaction completion the color of the system is changed to grayish white indicating $100 \%$ conversion [14]. The filtrate was then evaporated under reduced pressure. The residual solids were recrystallized from hot water to give the pure product of corresponding amino phenols in almost $100 \%$ yield.

\subsection{Characterization Techniques}

2.4.1. XRD (X-Ray Diffraction Analysis). X-Ray diffractograms of various solids were collected using a Bruker D8 advance instrument with $\mathrm{CuK} \alpha 1$ target with second monochromator $40 \mathrm{kV}, 40 \mathrm{~mA}$.

2.4.2. EPR (Electron Paramagnetic Resonance). The EPR spectra were recorded on EMX Bruker instrument operated at $X$-band frequency. The following parameters are generalized to all samples otherwise mentioned in the text. Microwave frequency is $9.79 \mathrm{GHz}$. Receiver gain is 20 . Sweep width is 6000 , center at $3480 \mathrm{Gs}$. Microwave power is $0.202637 \mathrm{~W}$.

2.4.3. Pulsed Chemisorption. The $\mathrm{H}_{2}$ chemisorption experiments were carried out at $373 \mathrm{~K}$ using a pulse reactor to determine the Ni metal area and Ni metal particle size. In a typical experiment, approximately $150 \mathrm{mg}$ of the catalyst sample was

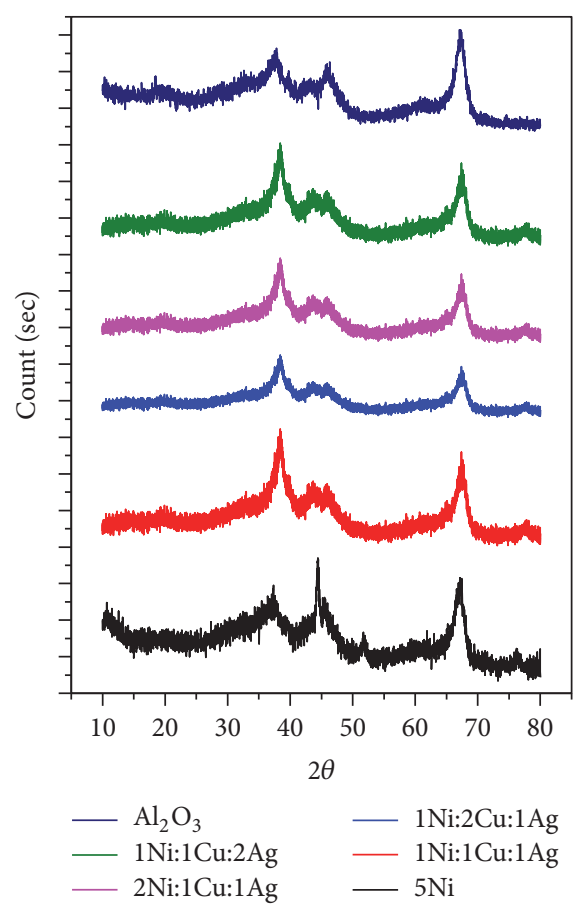

FIGURE 1: XRD patterns of pure Ni, some trimetallic systems, and bare alumina.

loaded in a micro quartz reactor $(8 \mathrm{~mm}$ i.d., and $250 \mathrm{~mm}$ long) and the catalyst sample was first subject to hydrogen flow at $420 \mathrm{~K}$ for $1 \mathrm{~h}$ and kept at the same temperature for $1 \mathrm{~h}$ under He flow and then the reactor was cooled to $373 \mathrm{~K}$ under helium gas flow. The outlet of the reactor was connected to a microthermal conductivity detector (TCD) of GC-17A (Quantachrome ChemBET 3000, USA) through an automatic six-port valve after cooling of the sample to $303 \mathrm{~K}$, pulses of gas $\left(5 \% \mathrm{H}_{2}\right.$ balance $\left.\mathrm{He}\right)(500 \mathrm{~mL})$, until there is no further change in the intensity of TCD peak due to gas pulse.

\section{Results and Discussion}

3.1. X-Ray Diffraction (XRD). Figure 1 represents the XRD patterns of bare alumina, $5 \% \mathrm{Ni}$, and some trimetallic systems. From these figures it could be shown that Ni metal phase was observed only in pure $5 \% \mathrm{wt} \mathrm{Ni}$. While in the rest of the samples there was no observation of such phase. This could be explained by the lower amount of metal which could not be detected by XRD techniques. Another reason is that the metal phases could be existing in amorphous nanoscale with bi- or trimetallic system. This will be declared further in EPR section.

3.2. Electron Spin Resonance (EPR). EPR spectra of all samples are given in Figure 2. In this figure we can observe an EPR signal characterized for the nanosized nickel [13].

3.3. Program for Trimetallic System. In this research we aimed to study and evaluate trimetallic system of $\mathrm{Ni}, \mathrm{Cu}$, and $\mathrm{Ag}$ as an effective catalyst for hydrogenation of nitrophenols. 
TABLE 1: Examples of some measured bimetallic and trimetallic systems.

\begin{tabular}{lccc}
\hline $\begin{array}{l}\text { Catalyst (5 wt\% loading on } \\
\text { alumina) }\end{array}$ & \multicolumn{3}{c}{ Time to reach 100\% conversion } \\
(sec) \\
Ni & PNP & MNP & ONP \\
$1 \mathrm{Ni}: 1 \mathrm{Cu}$ & 505 & 149 & 80 \\
$2 \mathrm{Ni}: 1 \mathrm{Cu}$ & 426 & 67 & 125 \\
$1 \mathrm{Ni}: 2 \mathrm{Cu}$ & 145 & 23 & 43 \\
$1 \mathrm{Ni}: 1 \mathrm{Ag}$ & 669 & 106 & 197 \\
$1 \mathrm{Ni}: 2 \mathrm{Ag}$ & 403 & 64 & 119 \\
$2 \mathrm{Ni}: 1 \mathrm{Ag}$ & 603 & 96 & 178 \\
$1 \mathrm{Ni}: 1 \mathrm{Cu}: 1 \mathrm{Ag}$ & 136 & 22 & 40 \\
$1 \mathrm{Ni}: 2 \mathrm{Cu}: 1 \mathrm{Ag}$ & 275 & 44 & 81 \\
$1 \mathrm{Ni}: 1 \mathrm{Cu}: 2 \mathrm{Ag}$ & 300 & 47 & 89 \\
$2 \mathrm{Ni}: 1 \mathrm{Cu}: 1 \mathrm{Ag}$ & 327 & 52 & 96 \\
$2 \mathrm{Ni}: 1 \mathrm{Cu}: 2 \mathrm{Ag}$ & 138 & 22 & 41 \\
$2 \mathrm{Ni}: 2 \mathrm{Cu}: 1 \mathrm{Ag}$ & 320 & 52 & 95 \\
\hline
\end{tabular}

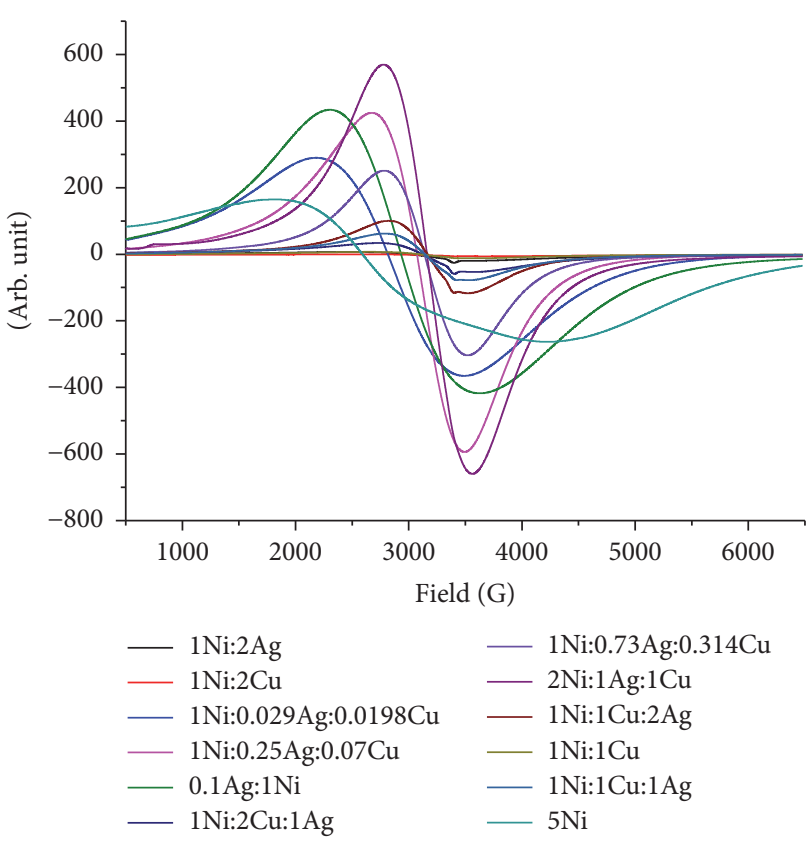

FIGURE 2: EPR spectra of different investigated samples.

In order to study this system we make a series of bimetallic systems Ni:Cu and Ni:Ag with different molar ratios (Table 1). The catalytic activity was taken as time to reach $100 \%$ conversion [13]. However we added a term "catalytic activity response" as a reciprocal of this time. This was taken as real measure of catalytic activity and thus as time decreases catalytic activity response increases.

From experimental test it was found that neither $\mathrm{Cu}$ nor Ag alone gives any catalytic activity in these reactions;



FIGURE 3: Fitted function of synergism of Ag.

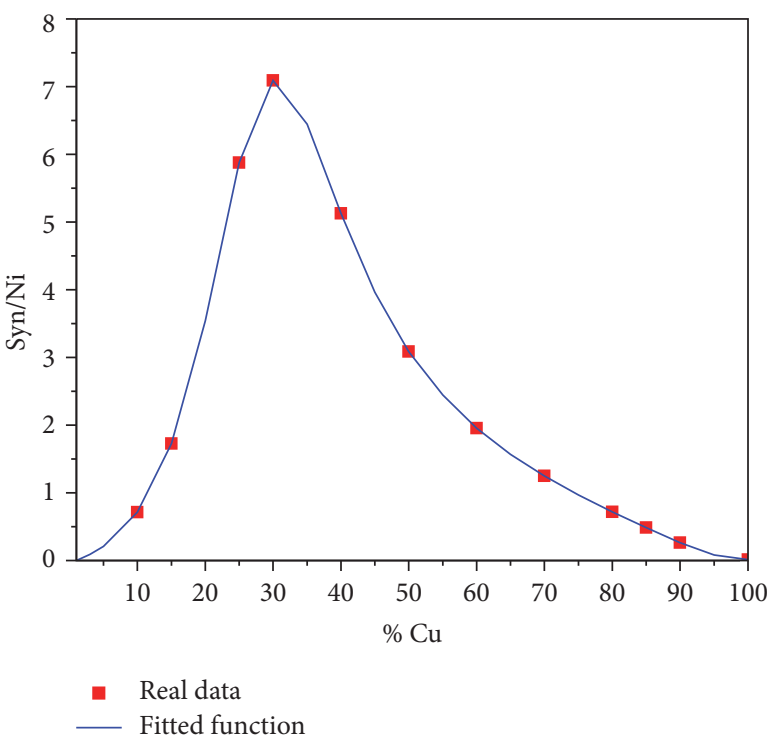

FIGURE 4: Fitted function of synergism of $\mathrm{Cu}$.

however in presence of $\mathrm{Ni}$ as a bimetallic system they could enhance the catalytic activity.

In order to study the effect of these metals on the activity of $\mathrm{Ni}$, we first determined what is called the linear catalytic activity which is the catalytic activity of catalyst based on its $\%$ nickel theoretically calculated from the pure nickel catalyst. Based on these values we can check any presence of synergism occurring due to addition of either $\mathrm{Cu}$ or $\mathrm{Ag}$ as bimetallic system with nickel. A function of synergism was evaluated for bimetallic system individually ( $\mathrm{Ni}: \mathrm{Cu}$ and $\mathrm{Ni}: \mathrm{Ag}$ ), was given below, and was fitted with regression with $R^{2}$ more than 0.99 as indicated below (Figures 3 and 4). 
Fitted Function of $\mathrm{Ag}$

$$
\begin{aligned}
& R 2=0.99999 . \\
& y=(a+c x+e x 2+g x 3+i x 4+k x 5+m x 6+o x 7+ \\
& q x 8+s x 9) /(1+b x+d x 2+f x 3+h x 4+j x 5+l x 6+ \\
& n x 7+p x 8+r x 9) \\
& a=8.38079978776094534 \mathrm{e}-12 . \\
& b=-0.13125008769893421 . \\
& c=0.00875045445894009892 . \\
& d=0.00879799437475077272 . \\
& e=-0.000542659485512226170037 . \\
& f=-0.000369150693507672097 . \\
& g=0.000130160541802780922 . \\
& h=1.04721425663883469 \mathrm{e}-05 . \\
& i=-2.37748383168755742 \mathrm{e}-06 . \\
& j=-2.04370666255700862 \mathrm{e}-07 . \\
& k=-1.04465938816921968 \mathrm{e}-07 . \\
& l=2.7069883330420037 \mathrm{e}-09 . \\
& m=4.38513923648865887 \mathrm{e}-09 . \\
& n=-2.30678157052159122 \mathrm{e}-11 . \\
& o=-6.44850744978172715 \mathrm{e}-11 . \\
& p=1.12348816431769573 \mathrm{e}-13 . \\
& q=4.3709878480847383 \mathrm{e}-13 . \\
& r=-2.33307317855799149 \mathrm{e}-16 . \\
& s=-1.15082085584729222 \mathrm{e}-15 .
\end{aligned}
$$

where $x$ is wt $\%$ of $\mathrm{Ag}$ in the sample and $y$ is \% syn/ $\mathrm{Ni}$.

\section{Simulated Function of Cu Synergism}

$$
\begin{aligned}
& R 2=0.9997 \\
& y=\left(a+c x^{\wedge}(0.5)+e x+g x^{\wedge}(1.5)+i x^{\wedge} 2\right) /\left(1+b x^{\wedge}(0.5)+\right. \\
& \left.d x+f x^{\wedge}(1.5)+h x^{\wedge} 2\right)[\mathrm{NL}] \\
& a=-0.0426081493584968437 . \\
& b=-0.54328913086813246 . \\
& c=0.0447085498764833328 \\
& d=0.108691551874143843 \\
& e=0.000882635994217492438 \\
& f=-0.00934404638076721272 . \\
& g=-0.00135640497689789237 \\
& h=0.000291267840703249792 . \\
& i=8.63726742343394856 \mathrm{e}-05 .
\end{aligned}
$$

where $x$ is wt $\%$ of $\mathrm{Cu}$ in the sample and $y$ is \% syn/ $\mathrm{Ni}$.

From Figures 3 and 4 curves it was found that the synergism function is increased as the \% added metal $(\mathrm{Cu}$ or $\mathrm{Ag})$ increases reaching maximum and then decreases again.

In order to study the trimetallic system we make a linear addition of both functions of individual synergism. Figure 5 represents the $3 \mathrm{D}$ graph of raw data given.

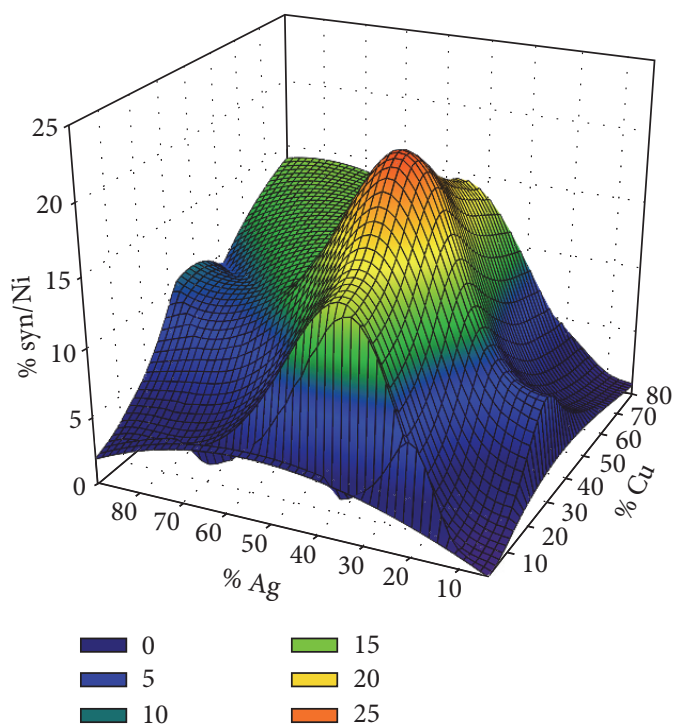

FIgURE 5: 3D presentation of trimetallic system Ni:Cu:Ag. Cu:Ag against synergism per $\% \mathrm{Ni}$.

The above data was simulated as $3 \mathrm{D}$ function as given below:

$$
\begin{aligned}
& z=a+b \exp (-\exp (-(x-c) / d)-(x-c) / d+ \\
& 1)+e \exp (-\exp (-(y-f) / g)-(y-f) / g+1) \\
& +h \exp (-\exp (-(x-c) / d)-(x-c) / d+1) * \\
& \exp (-\exp (-(y-f) / g)-(y-f) / g+1) . \\
& a=1.06593487136815043 \\
& b=6.21497398634458147 \\
& c=30.766242892928571 . \\
& d=10.6485929178985698 \\
& e=14.6057695738211414 . \\
& f=36.2251355611607967 . \\
& g=12.5973938666555902 . \\
& h=0.371621313243641629 . \\
& R 2=0.99606799
\end{aligned}
$$

where $x$ is \% copper, $y$ is the $\% \mathrm{Ag}$, and $z$ is the $\%$ syn/Ni.

Figure 6 represents the 3D model of simulated function which gives us high accuracy.

Figures 5 and 6 showed clearly that the 3D model of the linear synergism functions showed more than 3D peaks varied according to the composition of the system. The maximum synergism was found to be of value about $22 \%$ syn/Ni.

This 3D figure could give us the ability to evaluate the four parameters in one time ( $\%$ syn, $\% \mathrm{Ni}, \% \mathrm{Cu}$, and $\% \mathrm{Ag}$ ). However, subsequently, analysis of the real system should be compared which will be performed in the next section.

After applying the previous function on real trimetallic systems we observed that extra synergism occurs due to 


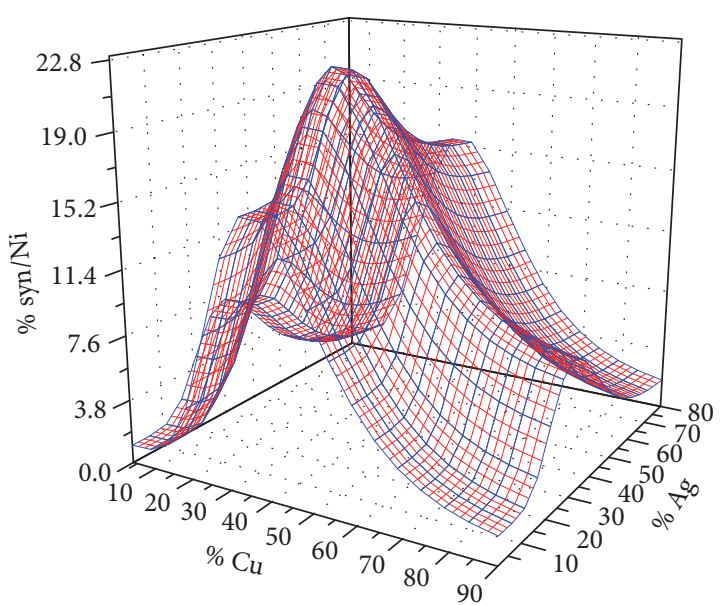

FIGURE 6: 3D model for the trimetallic system of Ni:Cu:Ag.

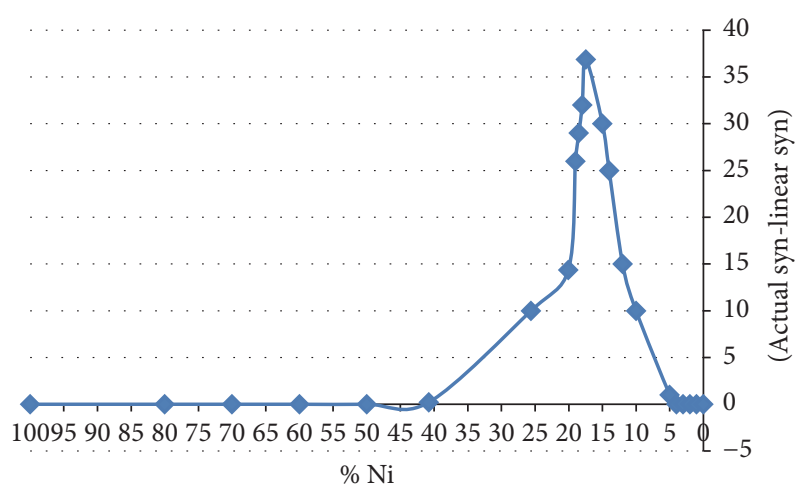

Figure 7: Difference between real and linear synergism against \% $\mathrm{Ni}$.

presence of both $\mathrm{Cu}$ and $\mathrm{Ag}$ together. In order to evaluate this extra synergism we correlate the difference in synergism with the $\% \mathrm{Ni}$ (Figure 7).

Thus, it was found that extra synergism is observed only in $\% \mathrm{Ni}$ between 5 and $40 \%$. In order to calculate it automatically we simulate this function as follows:

$$
\begin{aligned}
& y=\left(a+c \ln x+e(\ln x)^{\wedge} 2+g(\ln x)^{\wedge} 3\right) /(1+b \ln x+ \\
& \left.d(\ln x)^{\wedge} 2+f(\ln x)^{\wedge} 3+h(\ln x)^{\wedge} 4\right) \\
& R^{2}=0.998 \\
& a=0.0635566682938822554 \\
& b=-1.45700051352569521 \\
& c=0.0405819231287318062 \\
& d=0.798911010088653167 \\
& e=-0.052037125263925555 \\
& f=-0.195314109600566023 \\
& g=0.0106381602099602297 \\
& h=0.0179571310856602618
\end{aligned}
$$

where $y$ is difference between simulated linear synergism and real trimetallic synergism and $x$ is $\% \mathrm{Ni}$.

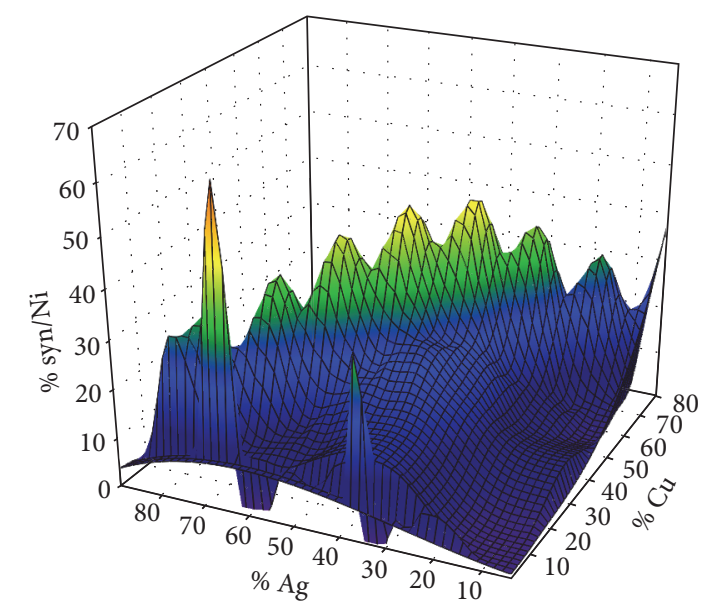

FIGURE 8: 3D representation of calculated real synergism function.

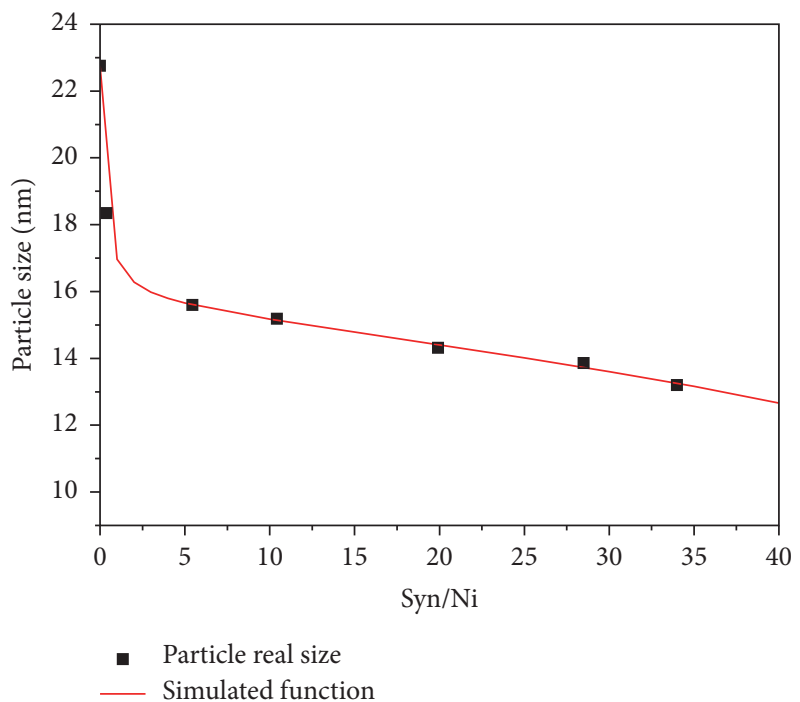

FIGURE 9: Correlation between particle size and function of synergism over $\% \mathrm{Ni}$.

After applying the above function on the threedimensional linear synergism function we could obtain the real function of synergism (Figure 8).

Obtaining the previous function enables us to deduce the catalytic activity and consequently the time to reach $100 \%$ for trimetallic system simply by input of the mole ratio of $\mathrm{Ni}: \mathrm{Cu}: \mathrm{Ag}$.

Particle Size Simulation. Particle size was evaluated by Kawabata equation correlating the peak-to-peak width of EPR spectra of nanoparticles with corresponding particle size:

$$
d=a * \sqrt{ } \Delta H_{p p},
$$

where $a$ is proportionality constant and $\Delta H_{p p}$ is the peak width. Knowing that " $a$ " for Ni is 1.6 [13] we can evaluate the particle size of each catalyst.

We correlate the particle size of different ratio of trimetallic catalysts with the function of real synergism Figure 9. 
TABLE 2: Experimental data for some selected samples for dispersion and metallic surface area.

\begin{tabular}{lccc}
\hline Catalyst & $\% \mathrm{Ni}$ & Dispersion & Metal surface area \\
\hline 1Ni:1Ag:1Cu & 25.65 & 30.41 & 10.13 \\
$2 \mathrm{Ni}: 1 \mathrm{Cu}$ & 64.9 & 55.27 & 18.42 \\
$1 \mathrm{Ni}: 1 \mathrm{Ag}$ & 35.43 & 32.51 & 10.83 \\
$\mathrm{Ni}$ & 100 & 4.12 & 1.37 \\
$2 \mathrm{Ni}: 1 \mathrm{Ag}$ & 52.32 & 3.63 & 1.21 \\
$1 \mathrm{Ni}: 1 \mathrm{Cu}$ & 48.04 & 2.71 & 0.9 \\
\hline
\end{tabular}
follows:

The function correlating the syn/ $\mathrm{Ni}$ with particle size is as

$$
\begin{aligned}
& \text { Eqn }=\text { Decay } 1+2(a, b, c, d, e) . \\
& y=a+b \exp (-c x)+d /(1+d e x) . \\
& y \quad-34.6564331 \\
& 6.41868775476660539 * \exp (-2.15 \\
& x \quad+\quad 50.9940759663696104 \\
& 50.9940759663696104 * 4.04301 \\
& 05 * x) \\
& a=-34.6564331294717461 . \\
& b=6.41868775476660539 . \\
& c=2.1574343708473217 . \\
& d=50.9940759663696104 . \\
& e=4.04301775665067334 \mathrm{e}-05 . \\
& R^{2}=0.9952975 .
\end{aligned}
$$$$
y \quad=\quad-34.6564331294717461+
$$$$
6.41868775476660539 * \exp (-2.1574343708473217 *
$$$$
x)+50.9940759663696104 \quad / \quad(1+
$$$$
50.9940759663696104 * 4.04301775665067334 \mathrm{e}-
$$

where $y$ is particle size by $\mathrm{nm}$ and $x$ is the syn/Ni.

By the above function we can deduce the particle size of any trimetallic system by the syn/Ni function.

In order to evaluate the secret of catalytic activity we make pulsed chemisorption to measure the metallic surface area and degree of dispersion and average crystallite size of Ni. This pulsed chemisorption was performed at reaction temperature (Table 2).

Correlating surface area per unite $\% \mathrm{Ni}$ with the synergism function we can obtain a good correlation as in Figure 10.

We can simulate the previous function as follows:

$$
\begin{aligned}
& y=a+b * \exp (-\exp (-((x-d \ln (\ln (2))-c) / d))) . \\
& r 2=0.999964110919114507 . \\
& a=0.0132405008193570401 . \\
& b=0.381497786254137327 . \\
& c=5.72848339592924586 . \\
& d=1.48550214791616277
\end{aligned}
$$

where $y$ is the metallic surface area by $\% \mathrm{Ni}$ and $x$ is the synergism function per $\% \mathrm{Ni}$.

By the above correlation we can simulate the metallic surface area to the synergism function easily to fully simulate

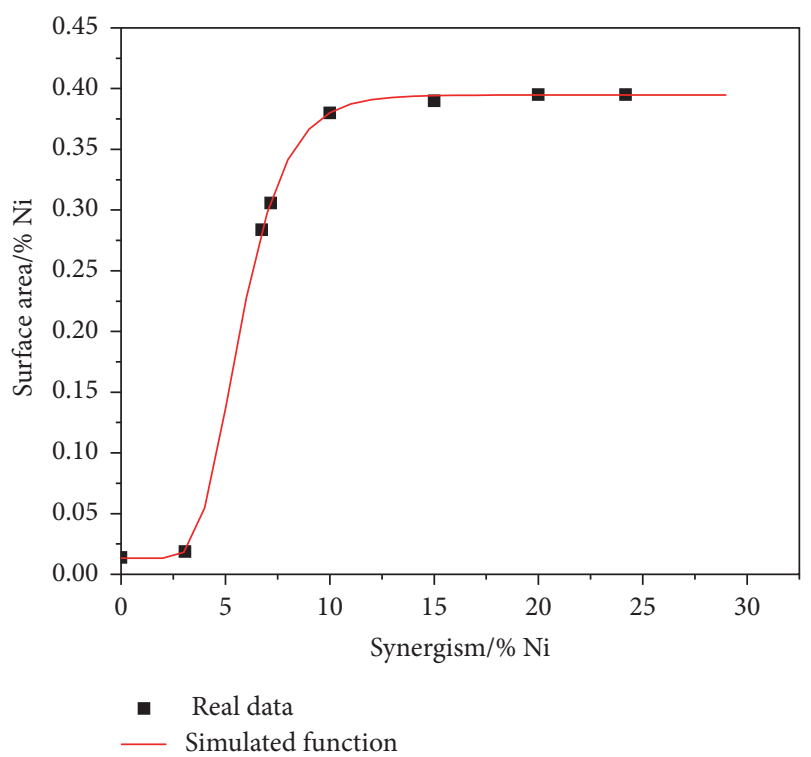

FIGURE 10: Metallic surface area per $\% \mathrm{Ni}$ against synergism per $\%$ $\mathrm{Ni}$.

the trimetallic system. The program written in Excel could simulate easily with a good precision the whole system for the all isomers of nitrophenol ( $\mathrm{p}-, \mathrm{m}_{-}^{-}$, and o-).

Figure 11 is the image of this Excel program which is attached with this manuscript as Supplementary Material (available online at https://doi.org/10.1155/2017/9464209).

Evaluation of the Program. In order to evaluate the program the catalytic activities of some random samples were measured and compared with data given from the program, Table 3.

From Table 3 we could realize that the program could predict precisely the time to reach $100 \%$ with average $\%$ error not exceeding $1.83 \%$ and max error not increasing by $8 \%$.

Mechanism of Reduction of Nitrophenols. Figure 12 represents the kinetic curve of the three nitrophenols which shows that all reduction processes follow first-order equation with respect to nitrophenols.

Durability Study of Some Samples Given. From Table 4 it was found that most of trimetallic system showed a good durability upon five times of successive use.

\section{Conclusions}

The trimetallic system ( $\mathrm{Ni}, \mathrm{Cu}$, and $\mathrm{Ag}$ ) was proved to be very effective for reduction of nitrophenols using hydrazine hydrate. Thus, nickel metal was found to be the only active center in this reaction. However, the presence of bimetallic and trimetallic alloy with nickel exhibits extra synergism. A program with high precision was successfully written to simulate the synergism function and the catalytic activity of the trimetallic system. The method of calculation used will open new aspect to deal with similar system in the 


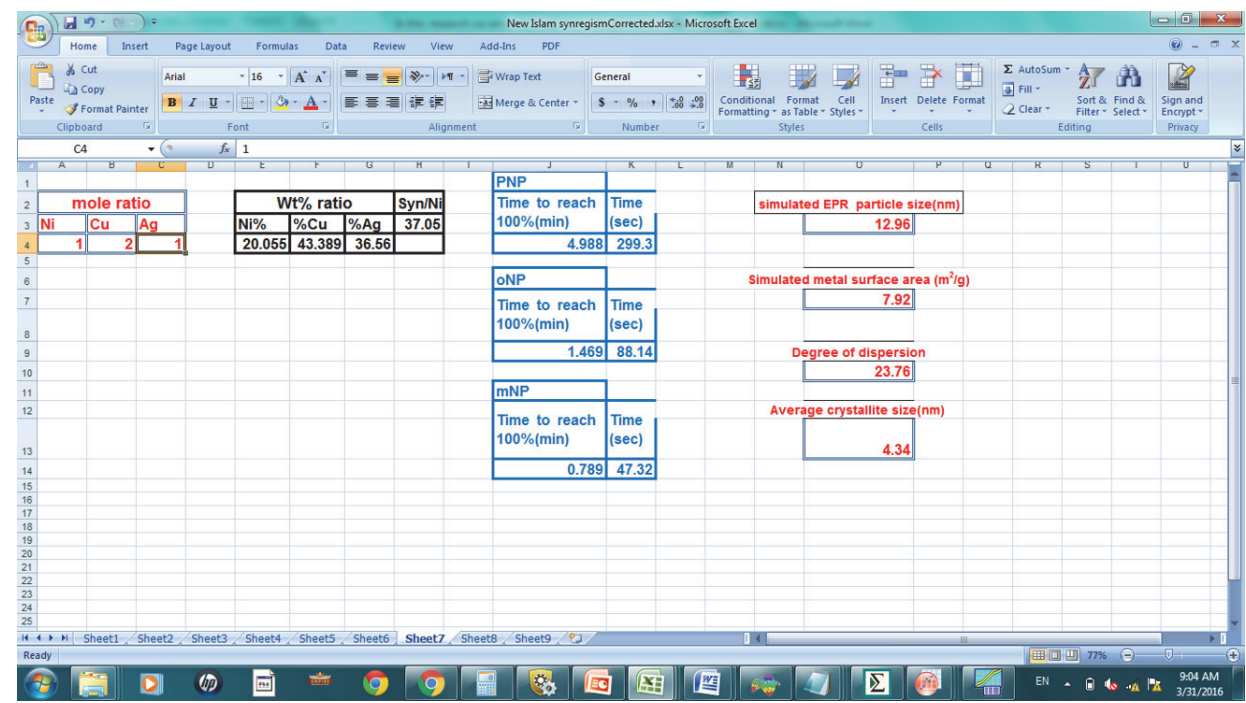

FIGURE 11: Image of Excel program.

TABLE 3: A comparison between real and calculated results of some random samples combined with \% error.

\begin{tabular}{|c|c|c|c|c|c|c|c|c|c|}
\hline \multirow{3}{*}{$\begin{array}{l}\text { Catalyst ( } 5 \mathrm{wt} \% \\
\text { loading on alumina) }\end{array}$} & \multicolumn{9}{|c|}{ Time to reach $100 \%$ conversion (sec) } \\
\hline & \multicolumn{3}{|c|}{ PNP } & \multicolumn{3}{|c|}{ MNP } & \multicolumn{3}{|c|}{ ONP } \\
\hline & Real & Calculated & $\%$ error & Real & Calculated & $\%$ error & Real & Calculated & $\%$ error \\
\hline$\overline{\mathrm{Ni}}$ & 505 & 505.1 & 0.02 & 149 & 148.7 & 0.20 & 80 & 79.86 & 0.18 \\
\hline $1 \mathrm{Ni}: 1 \mathrm{Cu}$ & 426 & 425.5 & 0.12 & 67 & 67.27 & 0.40 & 125 & 125.3 & 0.24 \\
\hline $2 \mathrm{Ni}: 1 \mathrm{Cu}$ & 145 & 144.9 & 0.07 & 23 & 22.9 & 0.43 & 43 & 42.66 & 0.79 \\
\hline $1 \mathrm{Ni}: 2 \mathrm{Cu}$ & 669 & 668.3 & 0.10 & 106 & 105.7 & 0.28 & 197 & 196.8 & 0.10 \\
\hline 1Ni:1Ag & 403 & 403.1 & 0.02 & 64 & 63.72 & 0.44 & 119 & 118.7 & 0.25 \\
\hline $1 \mathrm{Ni}: 2 \mathrm{Ag}$ & 603 & 603.3 & 0.05 & 96 & 95.39 & 0.64 & 178 & 177.7 & 0.17 \\
\hline $2 \mathrm{Ni}: 1 \mathrm{Ag}$ & 136 & 135.7 & 0.22 & 22 & 21.45 & 2.50 & 40 & 39.95 & 0.12 \\
\hline 1Ni:1Cu:1Ag & 275 & 274.7 & 0.11 & 44 & 43.42 & 1.32 & 81 & 80.88 & 0.15 \\
\hline 1Ni:2Cu:1Ag & 300 & 299.1 & 0.30 & 47 & 47.29 & 0.62 & 89 & 88.08 & 1.03 \\
\hline $1 \mathrm{Ni}: 1 \mathrm{Cu}: 2 \mathrm{Ag}$ & 327 & 327.2 & 0.06 & 52 & 51.73 & 0.52 & 96 & 96.35 & 0.36 \\
\hline 2Ni:1Cu:1Ag & 138 & 137.3 & 0.51 & 22 & 21.71 & 1.32 & 41 & 40.43 & 1.39 \\
\hline 2Ni:1Cu:2Ag & 320 & 319.6 & 0.12 & 52 & 50.53 & 2.83 & 95 & 94.11 & 0.94 \\
\hline 2Ni:2Cu:1Ag & 179 & 178.3 & 0.39 & 29 & 28.19 & 2.79 & 53 & 52.51 & 0.92 \\
\hline 4Ni:1Cu:2Ag & 140 & 138.2 & 1.29 & 23 & 21.84 & 5.04 & 42 & 40.68 & 3.14 \\
\hline 1Ni:2Cu:3Ag & 1128 & 1122 & 0.53 & 180 & 177.3 & 1.50 & 333 & 330.3 & 0.81 \\
\hline 3Ni:1Cu:1Ni & 104 & 105 & 0.96 & 18 & 16.6 & 7.78 & 32 & 30.92 & 3.37 \\
\hline $1 \mathrm{Ni}: 3 \mathrm{Cu}: 2 \mathrm{Ag}$ & 718 & 716.8 & 0.17 & 115 & 113.3 & 1.48 & 213 & 211.1 & 0.89 \\
\hline 2Ni:1Cu:2Ag & 322 & 319.6 & 0.75 & 52 & 50.53 & 2.83 & 96 & 94.11 & 1.97 \\
\hline Average error & & & 0.32 & & & 1.83 & & & 0.94 \\
\hline
\end{tabular}

TABLE 4: A durability study for some trimetallic samples for reduction of PNP.

\begin{tabular}{|c|c|c|c|c|c|}
\hline \multirow{2}{*}{ Sample } & \multicolumn{5}{|c|}{ Time to reach $100 \%$ for PNP (sec) } \\
\hline & 1st use & 2nd use & 3rd use & 4 th use & 5 th use \\
\hline 1Ni:1Cu:1Ag & 275 & 280 & 290 & 300 & 330 \\
\hline 1Ni:2Cu:1Ag & 300 & 310 & 310 & 330 & 350 \\
\hline 1Ni:1Cu:2Ag & 327 & 328 & 330 & 335 & 340 \\
\hline 2Ni:1Cu:1Ag & 138 & 140 & 142 & 146 & 150 \\
\hline 2Ni:1Cu:2Ag & 320 & 322 & 324 & 330 & 340 \\
\hline 2Ni:2Cu:1Ag & 179 & 182 & 183 & 185 & 190 \\
\hline
\end{tabular}



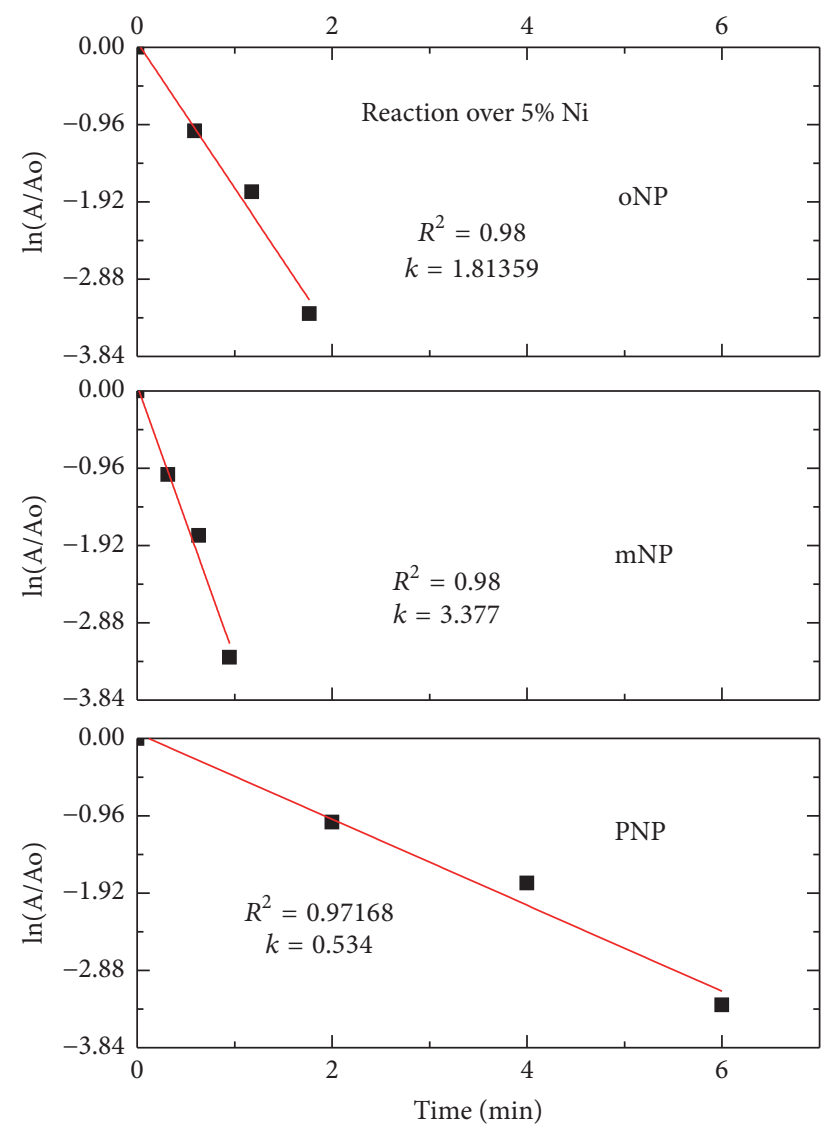

FIGURE 12: Kinetic curve of reaction of nitrophenols into aminophenol under our reaction conditions.

future. Some physical properties such as particle size and metallic surface area could be simulated successfully for whole trimetallic system.

\section{Conflicts of Interest}

The authors declare that there is no conflict of interests regarding the publication of this paper.

\section{Acknowledgments}

This project was funded by the Deanship of Scientific Research (DSR), King Abdulaziz University, Jeddah, under Grant no. 392/130/1436. The authors, therefore, acknowledge with thanks DSR technical and financial support. The authors would like also to acknowledge King Fahd Medical Center for the support in measuring the ESR samples.

\section{References}

[1] M. G. Prakash, R. Mahalakshmy, K. R. Krishnamurthy, and B. Viswanathan, "Studies on Ni-M $(\mathrm{M}=\mathrm{Cu}, \mathrm{Ag}, \mathrm{Au})$ bimetallic catalysts for selective hydrogenation of cinnamaldehyde," Catalysis Today, vol. 263, pp. 105-111, 2016.

[2] W. Chen, H. Bao, D. Wang, X. Wang, Y. Li, and Y. Hu, "Chemoselective hydrogenation of nitrobenzyl ethers to aminobenzyl ethers catalyzed by palladium-nickel bimetallic nanoparticles," Tetrahedron, vol. 71, no. 49, pp. 9240-9244, 2015.

[3] J. Zhou, X. Duan, L. Ye et al., "Enhanced chemoselective hydrogenation of dimethyl oxalate to methyl glycolate over bimetallic Ag-Ni/SBA-15 catalysts," Applied Catalysis A: General, vol. 505, pp. 344-353, 2015.

[4] Z. Wang, L. Yang, R. Zhang, L. Li, Z. Cheng, and Z. Zhou, "Selective hydrogenation of phenylacetylene over bimetallic $\mathrm{Pd}$ $\mathrm{Cu} / \mathrm{Al}_{2} \mathrm{O}_{3}$ and $\mathrm{Pd}-\mathrm{Zn} / \mathrm{Al}_{2} \mathrm{O}_{3}$ catalysts," Catalysis Today, vol. 264, pp. 37-43, 2016.

[5] H. Lin, J. Zheng, X. Zheng, Z. Gu, Y. Yuan, and Y. Yang, "Improved chemoselective hydrogenation of crotonaldehyde over bimetallic AuAg/SBA-15 catalyst," Journal of Catalysis, vol. 330, pp. 135-144, 2015.

[6] Y. Zhao, Y. Yeh, R. Liu, J. You, and F. Qu, "Facile deposition of gold nanoparticles on core-shell Fe3O4@polydopamine as recyclable nanocatalyst," Solid State Sciences, vol. 45, pp. 9-14, 2015.

[7] F. Qu, H. Sun, Y. Zhang, H. Lu, and M. Yang, "Electrochemically deposited Pd nanorod array/sol-gel silica thin film for the fabrication of electrochemical sensors," Sensors and Actuators, B: Chemical, vol. 166-167, pp. 837-841, 2012.

[8] C. Liu, H. Bao, D. Wang, X. Wang, Y. Li, and Y. Hu, "Highly chemoselective hydrogenation of active benzaldehydes to benzyl alcohols catalyzed by bimetallic nanoparticles," Tetrahedron Letters, vol. 56, no. 46, pp. 6460-6462, 2015.

[9] J. Meurig Thomas, R. D. Adams, E. M. Boswell, B. Captain, H. Grönbeck, and R. Raja, "Synthesis, characterization, electronic structure and catalytic performance of bimetallic and trimetallic nanoparticles containing tin," Faraday Discussions, vol. 138, pp. 301-315, 2008.

[10] K. J. Uffalussy, B. K. Captain, R. D. Adams, A. B. Hungria, J. R. Monnier, and M. D. Amiridis, "Synthesis and characterization of cluster-derived $\mathrm{PtRu}_{5}$ Sn catalysts," ACS Catalysis, vol. 1, no. 12, pp. 1710-1718, 2011.

[11] A. B. Hungria, R. Raja, R. D. Adams et al., "Single-step conversion of dimethyl terephthalate into cyclohexanedimethanol with $\mathrm{Ru}_{5} \mathrm{PtSn}$, a trimetallic nanoparticle catalyst," Angewandte Chemie, vol. 45, no. 29, pp. 4782-4785, 2006.

[12] Y. Ito, H. Ohta, Y. M. A. Yamada, T. Enoki, and Y. Uozumi, "Transfer hydrogenation of alkenes using Ni/Ru/Pt/Au heteroquatermetallic nanoparticle catalysts: sequential cooperation of multiple nano-metal species," Chemical Communications, vol. 50, no. 81, pp. 12123-12126, 2014.

[13] I. H. Abd El Maksod, E. Z. Hegazy, S. H. Kenawy, and T. S. Saleh, "An environmentally benign, highly efficient catalytic reduction of p-Nitrophenol using a nano-sized nickel catalyst supported on silica-alumina," Advanced Synthesis and Catalysis, vol. 352, no. 7, pp. 1169-1178, 2010.

[14] I. H. Abd El Maksod, T. S. Saleh, and E. Z. Hegazy, "Preparation, characterization and utilization of $(\mathrm{Ni}: \mathrm{Cu})$ bimetallic system loaded on zeolites," Journal of Alloys and Compounds, vol. 506, no. 2, pp. 923-927, 2010. 

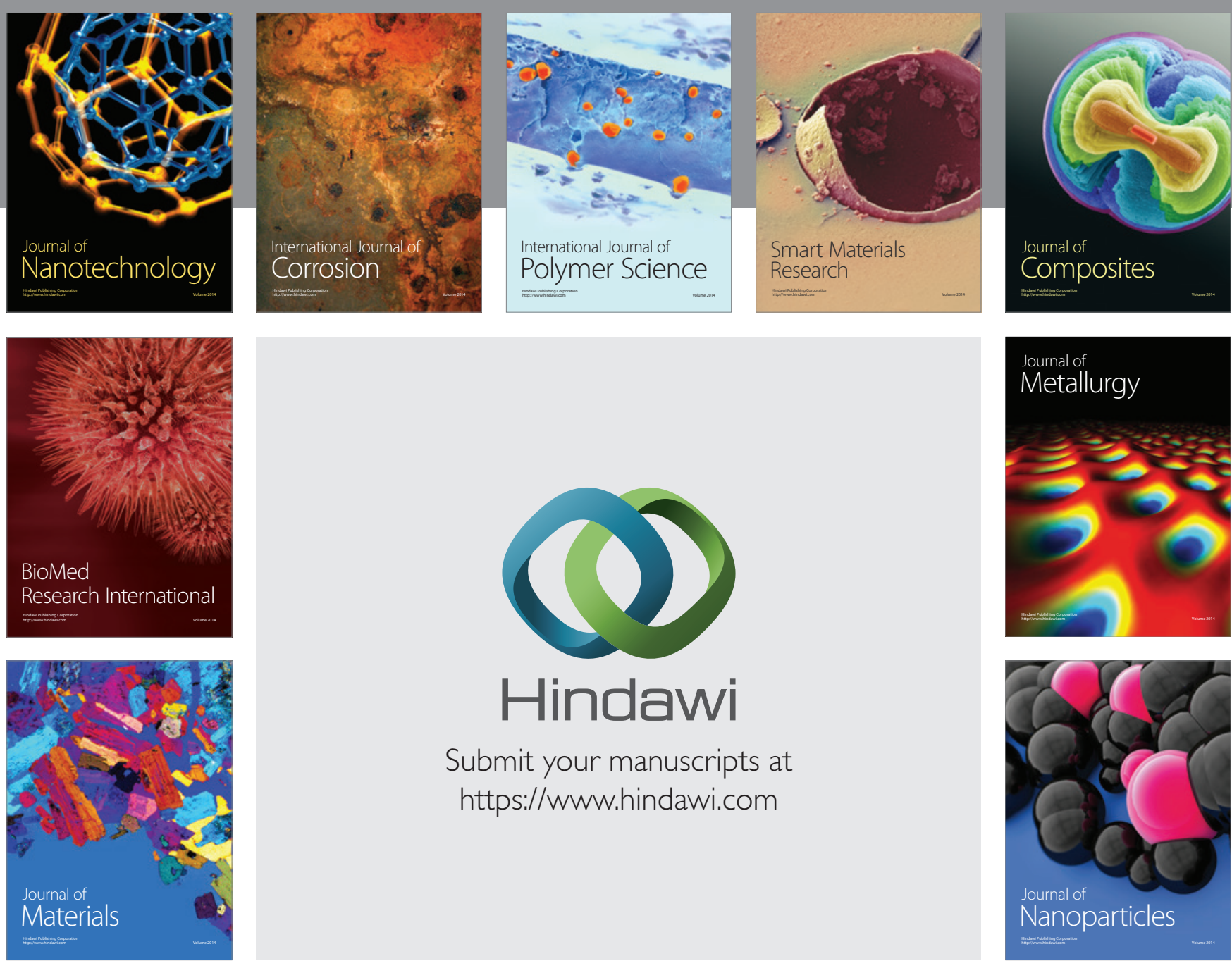

\section{Hindawi}

Submit your manuscripts at

https://www.hindawi.com

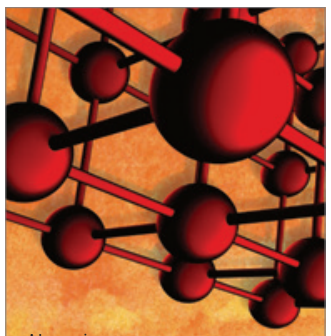

Materials Science and Engineering
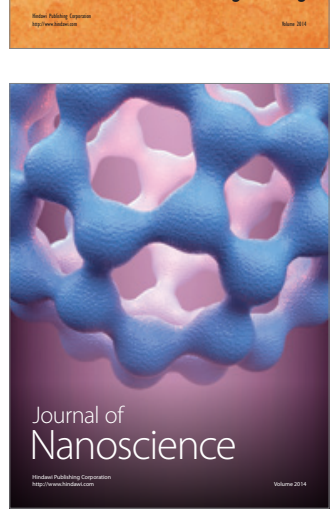
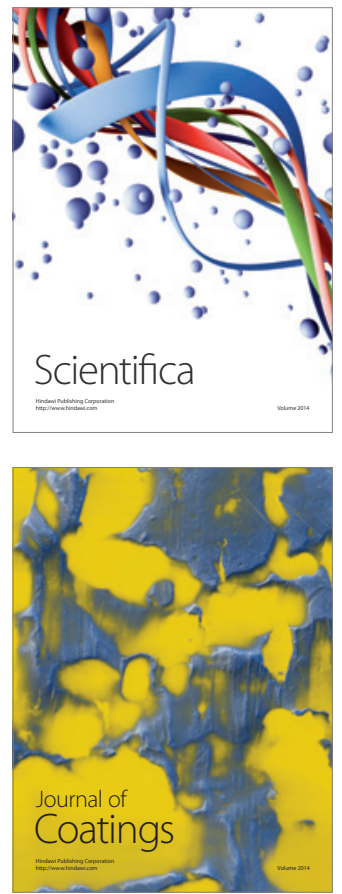
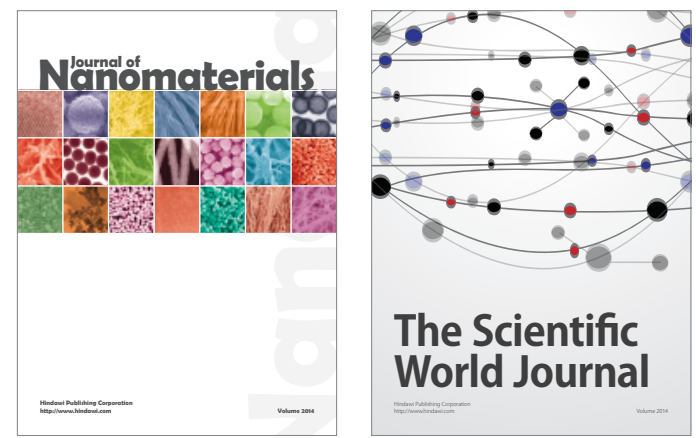

The Scientific World Journal
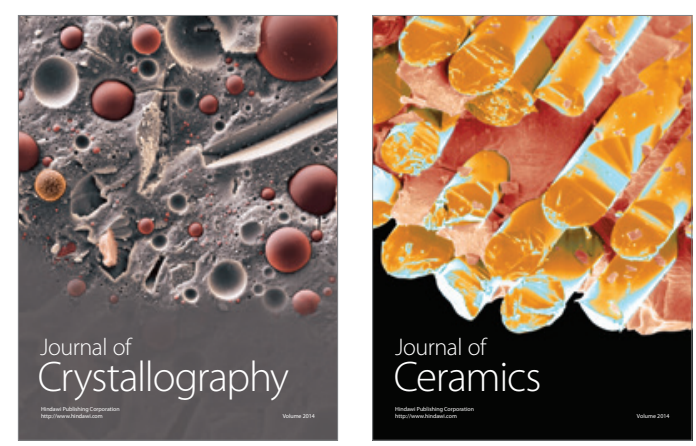
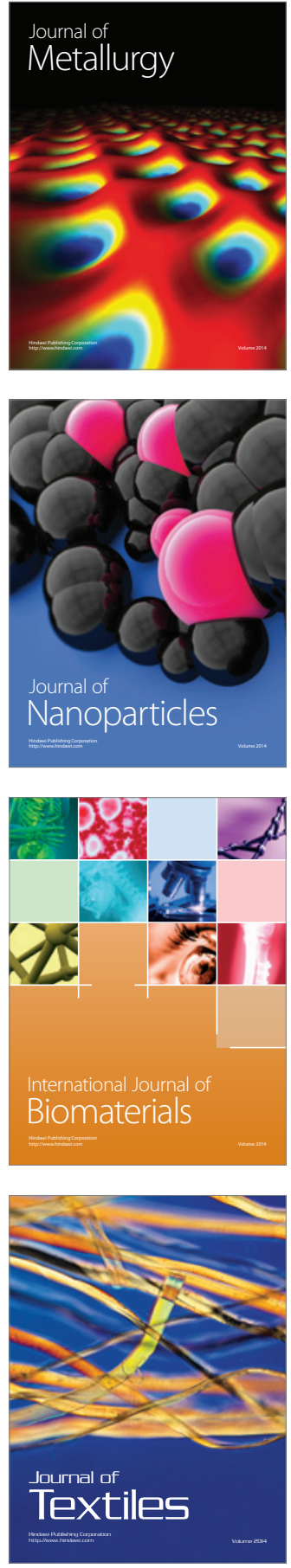